\title{
Hazards of anesthesia gas delivery systems
}

James Eisenkraft MD

$\mathrm{T}$ HE anesthesia delivery system comprises the anesthesia machine, vaporizers, ventilator, and waste gas scavenging system. Failure of the delivery system is a rare cause of anesthesia-related injury to, or death of, a patient. More commonly the delivery system is misused, the anesthesia caregiver makes an error, or the delivery system fails while the user is unaware that a failure has occurred. This lecture will review failures and complications of delivery systems from the viewpoint of how they may be detected and thereby harm to the patient prevented.

\section{Perspective}

The critical incident (CI) technique was first described by Flanagan in $1954^{1}$ and was developed to reduce loss of military pilots and aircrafts during training. It was modified and introduced into anesthesia by Cooper $e t a l^{2}{ }^{2}$ who went on to interview staff and resident anesthesiologists in a large metropolitan teaching hospital. Cooper et al. collected and analyzed 1,089 descriptions of CIs during anesthesia. ${ }^{3}$ A mishap was labelled a CI when it was clearly an occurrence that could have led, if not discovered or corrected in time, or did lead to an undesirable outcome, ranging from increased length of hospital stay to death or permanent disability. Other CI study inclusion criteria were: that each incident involved an error by a member of the anesthesia team or a failure of the anesthesiologist's equipment to function properly; it occurred during patient care; it could be clearly described; and the incident was clearly preventable. ${ }^{3}$ Of the 1,089 CIs, 70 represented errors or failures that had contributed in some way to a "substantive negative outcome" (SNO) defined as mortality, cardiac arrest, cancelled operative procedure, or extended stay in the postanesthesia care unit, intensive care unit or in the hospital. While some $30 \%$ of all CIs were related to equipment failures, including breathing circuit disconnections, misconnections, ventilator malfunctions, and gas flow control errors, only three
(4.3\%) of SNO incidents involved equipment failure, suggesting that human error was the dominant problem in CIs. Although equipment failures rarely cause death, CIs related to equipment are common and have prompted improvements in equipment design, construction and in monitoring.

In 1993, the Australian Anaesthesia Patient Safety Foundation published results of the Australian incident monitoring study (AIMS) that had collected 2,000 CIs. ${ }^{4}$ Of these, $177(9 \%)$ were due to equipment failure in general and $107(60 \%)$ involved the anesthesia delivery system. ${ }^{5}$ Failures included problems due to unidirectional valves, ventilator malfunctions, gas or electrical supply, circuit integrity, vaporizers, absorbers and pressure regulators. Concerning the problems with ventilation, it was recommended that critical areas be doubly or triply monitored and that monitoring equipment be self-activating. ${ }^{6}$

The role of equipment failures leading to malpractice litigation in the United States has been studied by the American Society of Anesthesiologists Closed Claims Project. A 1997 analysis of 3,791 claims, ${ }^{7}$ of which 76\% occurred during the period 1980 to 1990 , found that gas delivery equipment problems accounted for $72 / 3,791$ (2\%). ${ }^{7}$ Of these $72,39 \%$ were related to the breathing circuit, $17 \%$ to ventilators, $21 \%$ to vaporizers, $11 \%$ to gas tanks or lines and $7 \%$ to the anesthesia machine. Death or brain damage occurred in $76 \%$ of these 72 cases. Initiating events were circuit misconnects, disconnects and gas delivery system errors. Misuse was judged to have occurred in $75 \%$ and equipment failure in only $24 \%$. Anesthesia caregivers were considered responsible in $70 \%$ of user error cases and ancillary staff (e.g., technicians) to have contributed in $30 \%$. Predominant mechanisms of injury were hypoxemia, excessive airway pressure and anesthetic agent overdose. Overall, $78 \%$ of claims were deemed preventable by appropriate use of monitoring. ${ }^{7}$

As of April 2003 the Closed Claims Project database included 5,803 claims of which 88 were related to anesthesia gas delivery equipment. ${ }^{\mathrm{A}}$ Claims for

From the Department of Anesthesiology, Mount Sinai School of Medicine, NewYork, New York, USA.

Address correspondence to: Dr. James Eisenkraft, Department of Anesthesiology, Mount Sinai School of Medicine, Box 1010, One

Gustave L. Levy Place, New York, New York 10029-6574, USA. Phone: 212-241-7467; Fax: 212-426-2009;

E-mail: james.eisenkraft@msnyuhealth.org 
events that occurred in the late 1990's are still being processed and the most recent gas delivery system claims were for events in 1994. Thus far, however, it appears that gas delivery equipment problems are decreasing as a proportion of total claims. Anesthesia gas delivery claims represented $3 \%$ of all claims from the 1970 's, $2 \%$ from the 1980 's, and only $1 \%$ from the 1990's. There were only 14 anesthesia gas delivery system claims from the 1990's. These include one supplemental oxygen $\left(\mathrm{O}_{2}\right)$ line event, five anesthesia machine problems, four vaporizer problems, one ventilator problem, and three breathing circuit problems. The outcomes in anesthesia gas delivery equipment claims from the 1990's seem to be less severe than earlier claims. Among the 14 1990's claims were two deaths, two brain damage, two pneumothoraces, four awareness, one cardiac arrest with full recovery, three cancellations of surgery (no actual injury), and one claim with no apparent injury. Payments reflect the lower severity of injury, with a median payment of $\$ 50,000$ in the 1990 's compared to $\$ 306,000$ for earlier gas delivery equipment claims. Twelve of the 14 1990's claims resulted in payment. All payments from the 1990 's were $<\$ 500,000$. $^{\mathrm{A}}$

\section{Monitoring the anesthesia breathing system}

The anesthesia breathing system (patient circuit) represents the interface between the patient and the anesthesia delivery system. ${ }^{8}$ While not all equipment failures are preventable, appropriate monitoring of the patient circuit should lead to early detection of failures and enable prompt intervention before the patient suffers any harm. Aspects of the patient circuit that can be routinely monitored include pressure, volume, capnography, respiratory gas composition and gas flows. Used correctly (i.e., appropriate monitors, alarm threshold limits, alarms enabled and functioning) such monitoring should detect most failures. Each monitoring modality will be briefly considered, together with its applications and limitations.

\section{Pressure monitoring}

Most anesthesia breathing systems incorporate an analogue pressure gauge, as well as an electronic pressure monitoring and alarm system. The pressure gauge, if present, is usually mounted on the carbon dioxide $\left(\mathrm{CO}_{2}\right)$ absorber and may measure the pressure at that site (North American Dräger). In the Ohmeda GMS Absorber System, pressure is sensed on the patient side

A Personal communication from Karen L. Posner, ASA Closed Claims Project, April 18, 2003. of the inspiratory unidirectional valve and "piloted" to the pressure gauge and pressure monitoring system. Depending upon circuit configuration, the pressure monitor may fail to detect certain abnormal pressure situations. Thus monitoring pressure at the absorber will not detect positive end-expiratory pressure (PEEP) produced by a free-standing PEEP-valve that has been placed between the expiratory limb of the circle system and the expiratory unidirectional valve.

\section{Low pressure alarm}

Because breathing system disconnects and misconnects are not uncommon occurrences, monitoring of breathing system integrity is essential. Circuit low pressure monitors have sometimes been referred to as "disconnect alarms" but this may be a misnomer because they monitor pressure and the user may infer circuit integrity only if the monitor is used appropriately. They annunciate an audible and visual alarm within $15 \mathrm{sec}$ when a minimum pressure threshold is not exceeded. The pressure threshold should therefore be set by the user to be just less than the normal peak inspiratory pressure so that any slight decrease will trigger the alarm. If the threshold is not set to be close to the peak inspiratory pressure, a circuit leak or disconnect may go undetected if the low pressure alarm threshold is satisfied. For example, a small diameter tracheal tube (e.g., $3.0 \mathrm{~mm}$ internal diameter) connected to a circle system might be pulled out of the patient's airway, leaving the lungs unventilated. Because the tube has high resistance to gas flow, the pressure increase in the circuit with each positive pressure inspiration may satisfy the low pressure alarm threshold. On modern anesthesia workstations the circuit pressure waveform is displayed, as is the low pressure alarm threshold, so that the latter can be suitably adjusted by the user.

Modern delivery systems incorporate low pressure alarms that are automatically enabled when the ventilator is turned on, but there may be still in use some older designs of alarm systems that must be enabled by the user. Because the low pressure alarm is critical during use of intermittent positive pressure ventilation (IPPV), the user must be aware of the properties of the monitoring system on the individual machine that he/she is using. If there is any doubt about whether or not a monitor is interfaced with the ventilator $\mathrm{ON} / \mathrm{OFF}$ switch, the alarm can be tested by deliberately creating a disconnect. While modern breathing system monitors have a widely adjustable low pressure alarm threshold, older models may provide a choice of only three settings (e.g., 8,12 and $26 \mathrm{~cm} \mathrm{H}_{2} \mathrm{O}$ ), which may limit the sensitivity to detect slight decreas- 
es in breathing system pressure. Some low pressure monitoring alarm systems offer an optional $60 \mathrm{sec}$ delay in the event that a slow ventilatory rate, e.g., < 4 breaths $\cdot \min ^{-1}$, is set.

Whereas the breathing system low pressure alarm must be enabled (either automatically or manually) in association with IPPV, the following pressure monitoring modalities are in continuous operation.

\section{Continuing pressure alarm}

Annunciated when circuit pressure exceeds $10 \mathrm{~cm} \mathrm{H}_{2} \mathrm{O}$ for $>15 \mathrm{sec}$, it alerts to more gradual increases in pressure, such as due to a ventilator pressure relief valve malfunction (i.e., valve stuck closed) or a scavenging system occlusion. In these situations fresh gas continues to enter the breathing system from the machine flowmeters but is unable to leave. Rate of rise of pressure therefore depends upon the fresh gas flow rate. ${ }^{9}$

\section{High pressure alarm}

This alarm is annunciated immediately whenever the high pressure threshold is exceeded. On modern machines this threshold is adjustable by the user, with a default usually at $50 \mathrm{~cm} \mathrm{H}_{2} \mathrm{O}$. Some older pressure monitors are not user-adjustable and have a default setting of $+60 \mathrm{~cm} \mathrm{H}_{2} \mathrm{O}$. This might be too high to detect an otherwise harmful high-pressure condition, e.g., total obstruction of the tracheal tube, in which the breathing system pressure fails to exceed $+60 \mathrm{~cm} \mathrm{H}_{2} \mathrm{O}$.

\section{Subatmospheric pressure alarm}

This annunciates an immediate alarm when pressure is $<-10 \mathrm{~cm} \mathrm{H}_{2} \mathrm{O}$. It should alert to potential negative pressure barotrauma situations due to suction being applied to the circuit. Negative pressure in the circuit may be due to spontaneous respiratory efforts by the patient, a malfunctioning waste gas scavenging system, a side-stream sampling gas analyzer when fresh gas flow into the circuit is too low, a suction catheter passed into the airway, or suction via the working channel of a fibrescope passed into the airway via a diaphragm.

\section{Volume monitoring}

Monitoring of expired tidal and minute volumes is usually achieved using a spirometer placed in the vicinity of the expiratory unidirectional valve. Spirometry is used to monitor ventilation and circuit integrity. A breathing system disconnect should result in annunciation of the low volume alarm if appropriate alarm limits for low volume have been set. Limitations of spirometry are that the alarm thresholds may not be user-variable. Thus one older model of machine has a spirometer that has a "low volume" alarm threshold fixed at $80 \mathrm{~mL}$. Particularly when a hanging bellows design of ventilator is used, a circle system disconnection may fail to trigger a low volume alarm condition because as the weighted bellows descends during exhalation, it may draw a normal tidal volume through the leak site and through the spirometer, thus satisfying the low volume alarm threshold. Because the spirometer is usually located by the expiratory unidirectional valve at the absorber, it does not measure the patient's actual expired tidal volume, rather the volume measured includes both that exhaled by the patient and the gas volume compressed in the breathing system.

While the spirometer low volume alarm is generally more useful in alerting to a low volume/possible disconnect situation, a high volume alarm feature may also be useful. Unanticipated increases in tidal volume have resulted from increasing the gas flow into the circuit. ${ }^{10}$ This may be from the machine flowmeters, by increasing the I:E ratio, or via a hole in the bellows in a North American Dräger AV-E ventilator. Thus any gas entering the patient circuit during inspiration has the potential to be added to the patient's inspired tidal volume. This may be particularly hazardous to the pediatric patient for whom a small tidal volume is intended.

A spirometer that senses gas flow direction can alert to a reverse flow situation such as may be due to an incompetent expiratory valve or to a breathing system leak. The Ohmeda spirometer is designed so that it can be moved to a location by the patient's airway for use with a Bain circuit. While in the latter location, the reverse flow detection alarm feature of the Ohmeda spirometer must be disabled by the user. The user must remember to re-enable this alarm feature when the spirometer is returned to its usual position, i.e., by the expiratory unidirectional valve of the circle breathing system.

From the foregoing it is apparent that basic pressure and volume monitors in the breathing system are subject to certain limitations due to their design, location in the breathing system, and (sometimes) alarm features.

\section{Gas composition in the circuit}

Appropriate monitoring of $\mathrm{O}_{2}, \mathrm{CO}_{2}$, nitrous oxide $\left(\mathrm{N}_{2} \mathrm{O}\right), \mathrm{N}_{2}$ and anesthetic agent in the gas mixture at the patient's airway will alert to most gas delivery, composition, and agent dosaging problems.

$\mathrm{O}_{2}$

Most anesthesia delivery systems incorporate a galvanic fuel cell $\mathrm{O}_{2}$ sensor at the inspiratory unidirectional valve. This analyzer actually senses $\mathrm{PO}_{2}$ (although the 
display is in volumes \%), is calibrated to $21 \%$ using room air and, unlike other technologies, is not "fooled" by other gases. On contemporary machines the $\mathrm{O}_{2}$ analyzer is automatically enabled whenever the machine is capable of delivering an anesthetic gas mixture. Causes of inadequate $\mathrm{O}_{2}$ concentration in the circuit include a hypoxic gas being delivered via the pipeline or tanks, disconnected fresh gas hose during use of a hanging bellows ventilator, $\mathrm{O}_{2}$ flow control valve turned off, fail-safe system failure, proportioning system failure, $\mathrm{O}_{2}$ leak in the low pressure system of the machine, and a closed circuit with inadequate $\mathrm{O}_{2}$ inflow rate.

The $\mathrm{O}_{2}$ analyzer with low concentration alarm appropriately set is an essential safety feature of all anesthesia delivery systems. A high $\mathrm{O}_{2}$ concentration alarm may also be important in certain situations. Thus during an $\mathrm{O}_{2}$ /helium anesthetic for laser surgery of the airway, if the helium tank were to become depleted or if the $\mathrm{O}_{2}$ flush is used, a high $\mathrm{O}_{2}$ concentration would be delivered that may lead to a fire.

\section{Capnography}

Capnography is discussed elsewhere in more detail. ${ }^{11}$

It can provide much information about ventilation of the patient's lungs, as well as about anesthesia delivery system function. Failure to ventilate, which might be due to a circuit disconnect or misconnect, should result in absence of a capnogram and annunciation of an apnea alarm. An abnormal capnogram may be caused by $\mathrm{CO}_{2}$ rebreathing (e.g., exhausted $\mathrm{CO}_{2}$ absorbent; incompetent inspiratory or expiratory valves; misconfigured circuit; Bain circuit with inner tube disconnect).

\section{Anesthetic gases and nitrogen \\ Monitoring concentrations of $\mathrm{N}_{2} \mathrm{O}$ and a potent inhaled agent with the use of appropriate high and low concentration alarm settings will alert to most agent dosage problems. Low agent concentration may be due to the vaporizer being off or empty and could result in patient "awareness." Excessive agent concen- trations may be due to vaporizer malfunction, tipping, or liquid agent in the circuit. Some analyzers will annunciate an alarm in the presence of mixed agents (vaporizer contamination; more than one vaporizer on). Agent analyzers are important if a measured flow vaporizing system (e.g., Copper Kettle, Verni-Trol) is being used because gas flow-setting errors could result in potentially lethal concentrations of agent being delivered. ${ }^{12}$ Agent analysis is also reassuring whenever a new piece of equipment, e.g., a Tec 6 vaporizer (for desflurane), or the Aladin ${ }^{\circledR}$ vaporizing system (on the}

Datex-Ohmeda S5/ADU workstation) is being used. Monitoring of $\mathrm{N}_{2}$ concentration may alert to the presence of a leak in the breathing system.

\section{Flows/sidestream spirometry}

Many anesthesiologists use sidestream sampling gas monitors to analyze respired gases. The addition of a Pitot tube flow sensor to the sidestream sampling adapter makes it possible, with only a small increase in size of the adapter, to monitor and set alarm limits for pressure, flow, volume and gas composition, all of which are sensed at the airway (e.g., D-Lite ${ }^{\mathrm{TM}}$ DatexOhmeda, Finland). Such monitoring of multiple aspects of ventilation and the delivery system function by the patient's airway offers many potential advantages over the usual pressure and volume monitoring sites, including the ability to monitor the patient's inspired and expired tidal volumes, flow-volume and pressure-volume loops. ${ }^{13}$

\section{Alarms}

While delivery system failures, use errors and equipment failures cannot always be prevented, appropriate monitoring should facilitate detection of most such problems and permit intervention before patient harm occurs. Monitoring/alarm deficiencies include absence (i.e., no monitor); non-function (i.e., monitor present but broken); and "disabled" (i.e., monitor/alarm not turned on or intentionally turned off) ${ }^{6}$ and inappropriate alarm thresholds or volume settings.

In the AIMS study with respect to ventilation it was concluded that critical areas be doubly or even triply monitored and that monitoring equipment be selfactivating. ${ }^{6}$ This philosophy might be equally well applied to other critical variables that are monitored. Alarm setting features are important and easy ("user friendly") bracketing of suitable limits is highly desirable, as is annunciation of adequate volume audible (i.e., loud) as well as visual alerts.

\section{Other potential complications of the delivery system Carbon monoxyde (CO)}

Since 1990 there have been several reports of patients who developed increased levels of carboxyhemoglobin in response to accumulation of $\mathrm{CO}$ in the circle system. The CO is generated when desflurane, enflurane and, to a lesser extent, isoflurane, interact with dry $\mathrm{CO}_{2}$ absorbent, particularly Baralyme ${ }^{\circledR} .{ }^{14}$ While no case of patient harm has been reported to date, $\mathrm{CO}$ represents a potential hazard of which the anesthesia caregiver should be aware. ${ }^{15}$ Measures to decrease this potential hazard include using absorbent that has the standard complement of water, or addition of liquid 
water to the top of the absorbent. ${ }^{15}$ Fresh gas should be turned off at the end of each case to prevent drying out of the absorbent and consideration should be given to replacing the absorbent more frequently, especially if the machine has been left unused for some time, such as over a weekend. ${ }^{16} \mathrm{~A}$ more simple solution would be to use $\mathrm{CO}_{2}$ absorbents that do not contain strong base. Amsorb ${ }^{\circledR}$ (Armstrong Ltd., Coleraine, Northern Ireland) is a new absorbent that does not contain strong base and does not form $\mathrm{CO}$ (or compound A) in vitro. ${ }^{17}$

Respiratory gas monitors in current use (infrared analyzers, mass spectrometers, Raman spectrometers) cannot detect CO directly. When desflurane or isoflurane interact with absorbent to produce $\mathrm{CO}$, trifluoromethane is also produced. This compound has a mass /charge $(\mathrm{m} / \mathrm{z})$ ratio of 69 and is read erroneously as enflurane by mass spectrometers that use the $\mathrm{m} / \mathrm{z}$ 69 to measure enflurane. ${ }^{18}$ If enflurane were actually being administered, this potential "clue" would not be helpful.

\section{Prevention of anesthetic equipment failures and com- plications}

Complications due to the anesthesia delivery system are uncommon but when they occur are usually due to use error rather than actual equipment failure. ${ }^{19}$ User education/in-servicing is essential if sophisticated equipment, such as a new (computerized, electronic) anesthesia workstation, is to be used appropriately. Education of ancillary (nursing/technical) staff is also important because they may unwittingly contribute to the occurrence of a complication. Indicated and all required monitors must be available and used correctly with alarm limits and alarm volumes set appropriately for the individual patient's situation. Anesthesia equipment should be regularly serviced by authorized personnel and the equipment updated as necessary to confirm any existing requirements. The American Society for Testing and Materials has published the newest (March 2000) voluntary consensus standard for anesthesia workstations. ${ }^{20} \mathrm{~A}$ pre-use checkout of the delivery system should be developed by each institution to suit local needs. In this regard, in 1993 the US Food and Drug Administration (FDA) has published a generic pre-use checkout. ${ }^{21}$ Item \#1 on the FDA 1993 pre-use checkout is that a backup means of ventilation should always be available and functioning. Thus if all else fails, the patient's lungs can be ventilated with room air (or $\mathrm{O}_{2}$ if a tank is available) using a self-inflating resuscitation bag.

\section{Acknowledgement}

This refresher course outline is based upon the outline "Problems with Anesthesia Gas Delivery Systems", a Refresher Course Lecture presented at the 2003 Annual Meeting of the American Society of Anesthesiologists, San Francisco, CA USA. Reprinted with permission of the American Society of Anesthesiologists, Park Ridge, Illinois, USA.

\section{References}

1 Flanagan JC. The critical incident technique. Psychol Bull 1954; 51: 327-58.

2 Cooper JB, Newbower RS, Long CD, McPeek B. Preventable anesthesia mishaps. Anesthesiology 1978; 49: 399-406.

3 Cooper JB, Newbower RS, Kitz RJ. An analysis of major errors and equipment failures in anesthesia management. Anesthesiology 1984; 60: 34-42.

4 Webb RK, Currie M, Morgan CA, et al. The Australian Incident Monitoring Study: an analysis of 2000 incident reports. Anaesth Intensive Care 1993; 21: 520-8.

5 Webb RK, Russell WJ, Klepper I, Runciman WB. Equipment failure: an analysis of 2000 incident reports. Anaesth Intensive Care 1993; 21: 673-7.

6 Russell WJ, Webb RK, Van der Walt JH, Runciman WB. Problems with ventilation: an analysis of 2000 incident reports. Anaesth Intensive Care 1993; 1: 617-20.

7 Caplan RA, Vistica MF, Posner KL, Cheney FW. Adverse anesthetic outcomes arising from gas delivery equipment: a closed claims analysis. Anesthesiology 1997; 87: 741-8.

8 Eisenkraft JB, Sommer RM. Hazards of the anesthesia delivery system. In: Ehrenwerth J, Eisenkraft JB (Eds). Anesthesia Equipment: Principles and Applications. St. Louis: Mosby; 1993.

9 Eisenkraft JB. Potential for barotrauma or hypoventilation with the Dräger AV-E ventilator. J Clin Anesth 1989; 1: 452-6.

10 Scheller MS, Jones BR, Benumof JL. The influence of fresh gas flow and inspiratory/expiratory ratio on tidal volume and arterial $\mathrm{CO} 2$ tension in mechanically ventilated surgical patients. J Cardiothorac Anesth 1989; 3: 564.

11 Good ML, Gravenstein N. Capnography. In: Ehrenwerth J, Eisenkraft JB (Eds). Anesthesia Equipment: Principles and Applications. St. Louis: Mosby; 1993.

12 Eisenkraft JB. Anesthesia vaporizers. In: Ehrenwerth J, Eisenkraft JB (Eds). Anesthesia Equipment: Principles and Applications. St. Louis: Mosby; 1993.

13 Merilainen P, Hanninen H, Tuomaala L. A novel sensor for routine continuous spirometry of intubated patients. J Clin Monit 1993; 9: 374-80. 
14 Fang ZX, Eger EI 2nd, Laster MJ, Chortkoff BS, Kandel

$L$, Ionescu P. Carbon monoxide production from degradation of desflurane enflurane, isoflurane, halothane and sevoflurane by soda lime and Baralyme®. Anesth Analg 1995; 80: 1187-93.

15 Berry PD, Sessler DI, Larson MD. Severe carbon monoxide poisoning during desflurane anesthesia. Anesthesiology 1999; 90: 613-6.

16 Epstein $R A$. In my opinion. Carbon monoxide: what should we do? APSF Newsletter 1994; 9: 40.

17 Woeblck HJ, Dunning M 3rd, Gandhi S, Chang D, Milosavljevic D. Indirect detection of carbon monoxid exposure by mass spectrometry during isoflurane anesthesia. Anesthesiology 1995; 83: 213-7.

18 Kharasch ED, Powers KM, Artru AA. Comparison of Amsorb, sodalime, and Baralyme degradation of volatile anesthetics and formation of carbon monoxide and compound $\mathrm{A}$ in swine in vivo. Anesthesiology 2002; 96: 173-82.

19 Eisenkraft JB. A commentary on anesthesia gas delivery equipment and adverse outcomes (Editorial). Anesthesiology 1997; 87: 731-3.

20 ASTM F1850-00. Standard specification for particular requirements for anesthesia workstations and their components. American Society for Testing and Materials (ASTM), West Conshohocken, PA. March 2000.

21 FDA Anesthesia apparatus checkout recommendations, 1993. Available on the FDA website www.fda.gov/cdrh/humfac/anesckot.html. 